\title{
Determination of sucrose concentration in lemon-type soft drinks by dispersive Raman spectroscopy
}

\author{
Landulfo Silveira Jr., Leonardo Marmo Moreira*, Viviane G.B. Conceição, \\ Heliodora L. Casalechi, Ingrid S. Muñoz, Fabiano Fernandes da Silva, \\ Marcos Augusto S.R. Silva, Renato Aparecido de Souza and Marcos Tadeu T. Pacheco \\ Group of Biomedical Engineering, Universidade Camilo Castelo Branco - UNICASTELO, São Paulo, \\ SP, Brazil
}

\begin{abstract}
The objective of this study was to quantify the sucrose amount in commercial lemon-type soft drinks through dispersive Raman spectroscopy, comparing the amount listed in the nutritional table of each product to the predicted by a least-square model, in order to obtain a method for quality assurance applied to soft drinks. A dispersive Raman spectrometer was employed using $830 \mathrm{~nm}$ laser and imaging spectrograph coupled to a CCD camera, and a total of 48 samples from four brands of lemontype soft drinks were analyzed. A calibration curve using sucrose from refined sugar (sugarcane) diluted in spring water was elaborated in the range between 0 and $15.0 \mathrm{~g} / 100 \mathrm{ml}$, and a quantification model based on Partial Least Squares (PLS) regression was developed to correlate the Raman spectra and the amount of sucrose in each dilution. Then, the sucrose in each soft drink sample was predicted employing the calibration curve. The mean error of calibration for the PLS method was $0.30 \mathrm{~g} / 100 \mathrm{ml}$ (3.0\%). Results indicated that soft drinks samples have predicted sugar content ranging from 8.1 to $10.9 \mathrm{~g} / 100 \mathrm{ml}$, with an error of the predicted value compared to the nutritional table ranged from $1.1 \%$ to $5.5 \%$. Therefore, Raman spectroscopy in association with PLS regression was an effective method for quantifying the sucrose, with small prediction error. Thus, the present work allows to infer auspicious possibilities of Raman spectroscopy application in the quantification of relevant nutritional facts in beverages.
\end{abstract}

Keywords: Sucrose quantification, soft drinks, industrialized food, Raman spectroscopy, PLS

\section{Introduction}

The lemon-type soft drink was introduced in the Brazilian market in 1912. Since then, several similar products were available to the consumer because of the success of lemon-flavor in the soft drink segment. Basic ingredients found in this type of drink are artificially gasified filtered or spring water, sucrose, natural lemon juice (2.5\% on average), natural flavored, acidifier and conservator [1]. Accordingly to the manufacturers, these soft drinks do not contain significant amounts of protein, fat, dietary fiber or other vitamins or minerals.

The sucrose is the common type of sugar used as sweetener for soft drinks and is a basic conservant for most industrialized non-dietetic foods. It comes mainly from sugarcane that may contain from

\footnotetext{
*Corresponding author: Leonardo Marmo Moreira, Universidade Camilo Castelo Branco - UNICASTELO, Núcleo do Parque Tecnológico de São José dos Campos, Rod. Pres. Dutra, km 138, São José dos Campos, SP 12247-004, Brazil. Tel.: +55 123905 4648, ext. 209; E-mail: leonardomarmo@gmail.com.
} 


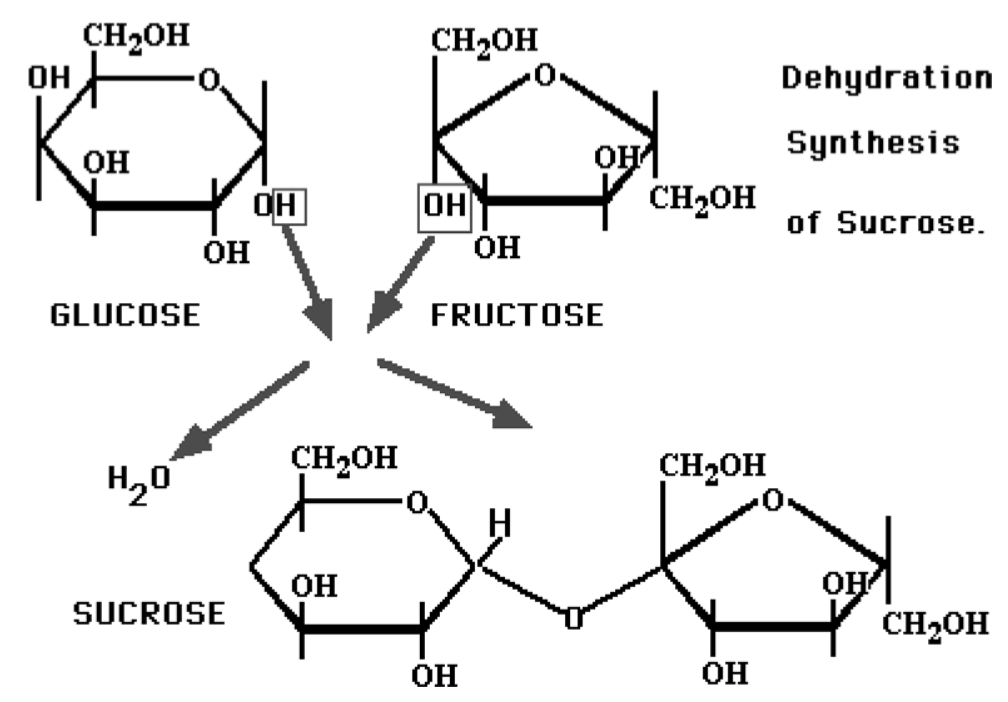

Fig. 1. Diagram showing the synthesis of sucrose from glucose and fructose, and their respective chemical structures.

$14 \%$ to $24 \% \mathrm{v} / \mathrm{v}$ of sucrose. Structurally, the sucrose is a disaccharide constituted by the union of the monosaccharides glucose and fructose, connected through their anomeric carbons. Figure 1 shows the chemical structures of glucose, fructose and sucrose. In Brazil, the commercial sugar is commonly available in a refined form (containing, at least, $98 \%$ of sucrose) or in crystals (containing, at least, $99 \%$ of sucrose) [2].

Sugar is largely employed in industrialized food in order to control the acidification during food processing, aiming to conserve and to change the acid taste of natural foods as milk and fruits [3]. The addition of excessive quantity of sugar transforms the food in a calorie bomb with eventual pathogenic effect [4]. The increase in the consumption of calories from carbohydrates has been positively correlated with the alarming rise of the "metabolic syndrome" [4,5]. Simple carbohydrates influence the glycemic index (GI). The high GI stimulates lipogenisis, resulting in an increased size of adipocytes, while diets with low GI inhibit this response [6]. Recently, it was shown that the overload of fructose in the diet of male mice during two months, despite of no induced changes in blood glucose and insulin baseline, resulted in impaired glucose tolerance [7]. With the regular, non-diet/light soft drinks, this biochemical phenomenon is not different as function of the high amount of sugar added and its highly consumed by general population $[3,8]$ and dangerously by the ingestion in childhood and adolescent, which could cause increased obesity risk in adulthood [9]. It was also demonstrated that highest concentration of carbohydrates in the diet, especially in its simplest form, constitutes a substantial risk factor for the development of obesity and diabetes [8].

According to data from Brazilian Ministry of Health, there was a considerable increase in the consumption per capita of soft drinks (400\%) in 2000, when compared to the consumption in 1970 [10]. This fact shows the trends in changing eating habits, which is associated to a significant substitution of natural food by industrialized one ("fast food"), which is rich in sugar and fat [11].

The determination of sucrose content is a routine activity in the soft drink industry, which uses relatively laborious techniques. Conventional methods, such as gravimetric, titulometric and spectrophotometric techniques, together with the HPLC with refraction index detector have been widely employed in industries [12]. It is interesting to note that the called classic methods, such as gravimetric and titulometric methodologies, are still applied in spite of the tedious character of these procedures. Furthermore, 
these methods require great quantity of reagents, implying that, in a determined interval of time, these analytical procedures represent a very higher cost to the factories as compared with some spectroscopic alternatives, which are less time consuming [13].

Several authors proposed optical techniques such as Raman spectroscopy for quality control [14-17]. Raman spectroscopy is a light-scattering phenomenon in which a laser photon of well-defined energy is scattered by a molecule or crystal. Usually, this scattering is mediated by vibrational transitions done by bonded atoms $[18,19]$. Raman technique presents advantages over classical approaches due to the fact that little or no sample preparation is needed, one could perform a non destructive analysis of samples, rapidness in collecting a Raman spectrum, and results can be obtained in real time and the potential for the identification of molecular groups present in the sample spectrum [19]. By analyzing the spectral information obtained through Raman spectroscopy, several aspects related to the physico-chemical properties of the samples can be evaluated like, for example, the chemical structure characterization [19] and thermal stability of bonds [20], among others. Raman spectroscopy can also propitiate quantitative determinations of the chemical components of the sample, depending of the characteristics of its compounds $[14,15]$. In fact, Raman spectroscopy could provide a "fingerprint" of a specific substance, favoring the analysis of this respective compound presented in several kinds of samples [19].

In this way, Raman spectroscopy could become a standard technique for food quality control, identifying the Raman bands of selected compounds of nutritional interest for the consumers. This analysis would be fast and precise, optimizing evaluations focused on the determination of food nutritional content $[14,21,22]$. In fact, with appropriate excitation wavelength (infrared, 785 and $830 \mathrm{~nm}$ ) and postprocessing routines, the emitted intrinsic fluorescence from organic samples could be minimized and the Raman bands evidenced with high signal to noise ratio [19].

Up to date, Raman spectroscopy has been applied in the determination of concentration of commercially available medicines, aiming identification and quantification of active ingredients [17,23,24], identification of biochemicals presented in biological samples [20,25], quality control in edible oils [26,27] and honey [13] among others. These procedures could be done in a noninvasive way, with minimal or no sample preparation and in real time, being that the use of dispersive Raman spectroscopy with nearinfrared excitation in the soft drink quality control could bring easiness of identifying the sweetener added in the products, as well as its precise quantification [18,28].

In this context, Raman spectroscopy has been used for in situ differentiation between sucrose and lactose as well as analyzing the amorphous and crystalline phases of sucrose [18]. Furthermore, this tool has been employed to the identification and quantification of sugars in various foods and drinks, such as chewing gums, yogurts, soft drinks and honey [3,28-30].

Water is an ideal solvent for Raman spectroscopy. Indeed, Raman spectroscopy constitutes a vibrational technique that presents a weak water scattering due to the Raman selection rules, causing no significant interference in the spectrum in the fingerprint $\left(400-2000 \mathrm{~cm}^{-1}\right)$ range [19]. As consequence, measurements in aqueous environments become more attractive, which is very interesting for identification of diseases in biological samples [19,25,31] and quality control in beverages [32].

Quantitative information could be obtained from the whole Raman spectra by applying chemometrics or multivariate calibration. For systems where the light scattering vary linearly with concentration, and a few variables are responsible for the spectral variations, Partial Least Squares (PLS) is most frequently used [33-35]. PLS algorithm is based on Principal Component Analysis (PCA), which extracts the most important variables from the dataset, correlating these variables with the concentration of first principal components, which represent the largest variations in the sample spectra [33]. PLS has been employed in quantitative analysis of Raman spectra of cereal-based foods [21], calculating the total dietary fiber, 
fat, protein, and sugar and of alcoholic beverages [32], calculating the amount of ethanol, in this case presenting better results than classical techniques (gas chromatography). Thus, quality control could be achieved by collecting the Raman spectra at line and developing a quantitative calibration curve by using a multivariate technique.

The objective of this study is to evaluate the feasibility of dispersive Raman spectroscopy to calculate the sucrose content in 48 samples of four brands of commercial lemon-type soft drinks. Firstly, it was developed a calibration curve with different amounts of sucrose diluted in spring water employing the multivariate regression PLS technique. Furthermore, the PLS is applied to the Raman spectra of soft drinks samples in order to correlate the diluted sucrose with the amount of carbohydrate listed in the nutrition table label of products. It is shown the potential of near-infrared, dispersive Raman spectroscopy applied to the quality assurance in the soft drink industry.

\section{Material and methods}

The lemon-type soft drink was chosen due to absence of dyes, which could provoke to strong fluorescence and cover the Raman bands from sucrose and reduces the light absorption.

In order to develop a calibration curve aiming the quantification of sugar added to lemon-type soft drinks, it was prepared a sequence of seriate dilutions of refined sugar from sugarcane (brand: União) in spring water (brand: Minalba) with a semi-analytical balance (Gehaka ${ }^{\circledR}$ Model BG-400). A total of 15 dilutions, from 1.0 to $15.0 \mathrm{~g} / 100 \mathrm{ml}$, were prepared, covering the range of sucrose presented in most lemon-type soft drinks (about $10.0 \mathrm{~g} / 100 \mathrm{ml}$ ). Each sucrose solution was prepared as follows: sugar was weighed in the semi-analytical balance and transferred to a volumetric flask of $100 \mathrm{ml}$, completed with the water to the exact volume and homogenized. It was not necessary to heat the solutions, due to the high solubility of sucrose in water [36].

A total of 48 samples from four brands of lemon-type soft drinks were bought in local markets (12 cans of each brand) with different manufacturing date, being that the amount of carbohydrate (sucrose) presented at the nutritional table of each product was recorded. Then, the prepared solutions of sucrose as well as the soft drinks samples were placed in a $1 \mathrm{~mm}$ thickness, $3 \mathrm{ml}$ volume quartz cuvette due to low fluorescence background provided for such material and underwent dispersive Raman spectroscopy, using a Raman spectrometer (Fig. 2). The Raman spectrometer is composed of a semiconductor laser diode (Micro Laser Systems Inc., Model L4830S, CA, USA), with output power of about $100 \mathrm{~mW}$ and wavelength of $830 \mathrm{~nm}$ for sample excitation. The laser beam was directed to the sample with the aid of a prism and the beam was focused onto the sample using a lens $(f=26 \mathrm{~mm})$. The scattered signal from the sample was coupled to the spectrograph (Chromex, Model 250IS, MA, USA) by a set of lenses $(f=100 \mathrm{~mm})$. The spectrograph has a notch filter at $830 \mathrm{~nm}$ in the entrance slit (Spectral Iridian Technologies, model PN - ZX 000080, ON, Canada) to reject the scattered light from the laser. The spectral resolution was approximately $8 \mathrm{~cm}^{-1}$ using a slit of about $150 \mu \mathrm{m}$ [37]. The signal dispersed by the spectrograph was detected by a $1024 \times 256, \mathrm{~N}_{2}$ cooled CCD camera (Princeton Instruments, model LN/CCD-1024-EHR1, NJ, USA), connected to a controller (Princeton Instruments, model ST130, NJ, USA) and a PC for the acquisition and storage of spectra. The spectral collection time was set to $50 \mathrm{~s}$ and the experiment was done at the same experimental conditions.

The procedures for calibration and pre-processing of all spectra were performed as follows. For the calibration of the Raman wavenumber, the known Raman peaks of naphthalene were identified and correlated by a third-order polynomial with each pixel peak position. In order to remove the fluorescence 


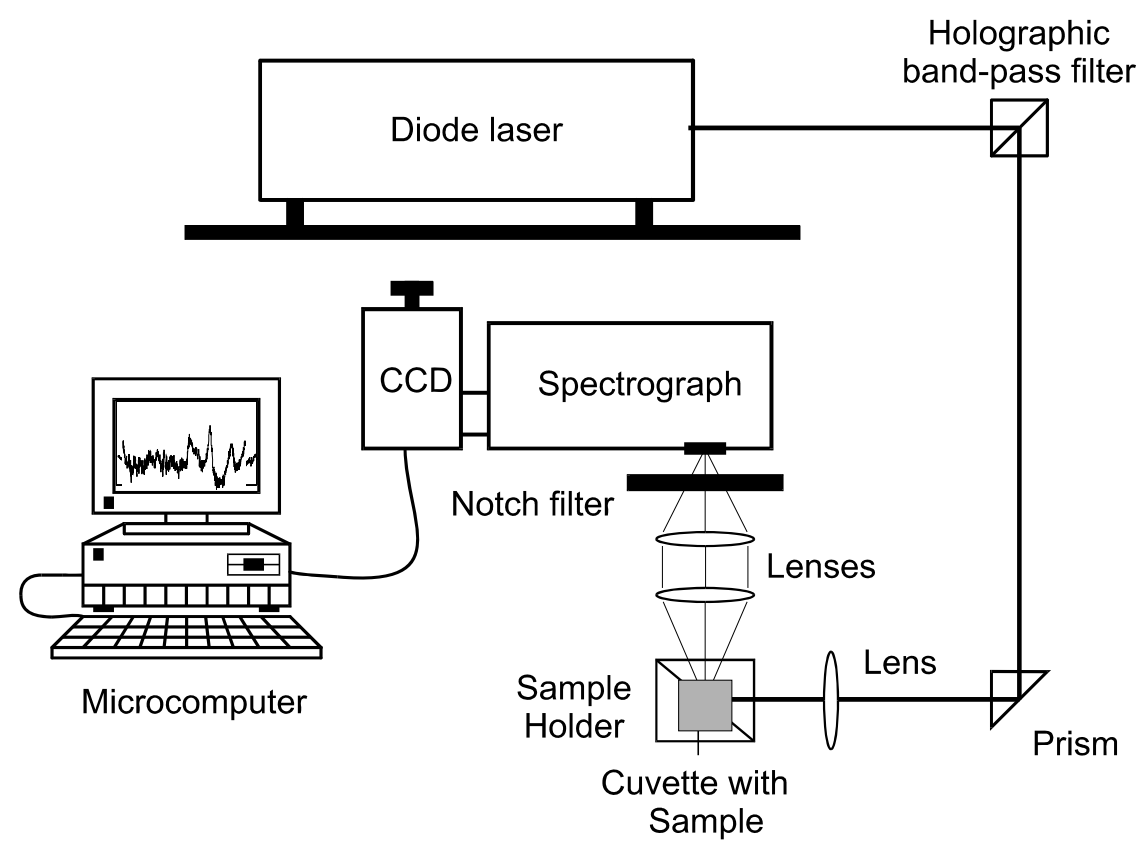

Fig. 2. Schematic diagram of dispersive Raman spectrometer. Laser power: $100 \mathrm{~mW}$, wavelength: $830 \mathrm{~nm}$, resolution: $8 \mathrm{~cm}^{-1}$.

background, a third-order polynomial equation was applied in the intensities of each spectrum and then subtracted from gross spectrum, remaining the high frequency Raman bands. This procedure is a relevant pre-requisite to the development of the analyses, since organic samples present fluorescence, even with near-infrared excitation. The calibration and background removal was done using a lab-made routine under Matlab 4.2.

With the previous knowledge of the solutions concentrations and the correspondent Raman spectra, a multivariate calibration model was established using the PLS. The Raman spectra were considered as independent variables, while the concentrations were analyzed as dependent variables. For developing the PLS calibration model, the function pls (Matlab 4.2 PLS toolbox) was applied, considering the first two latent variables, since the first latent variable in the PLS method is the mean spectrum, and there are only a few variables (the sucrose) that account for differences in the samples solutions. Details of the PLS calibration model can be found elsewhere [34,35].

Using the same spectra of the calibration model, the PLS predicted the concentrations of the calibration dataset, which were obtained though the Matlab function plspred. Then, it was plotted the concentration predicted by PLS versus the values of known concentrations and it was calculated the standard error of calibration (SEC), or the model ability to predict the concentrations. The model was then applied to the spectra of soft drinks, using the known spectra and concentrations of sucrose in water, and the predicted concentrations were correlated to the amount found in the nutritional table.

\section{Results and discussion}

Figure 3 shows the spectrum of sucrose solution in spring water with concentration of $15.0 \mathrm{~g} / 100 \mathrm{ml}$. The spectrum presents its principal bands at $824,1052,1119$ and $1445 \mathrm{~cm}^{-1}$, which have been reported 


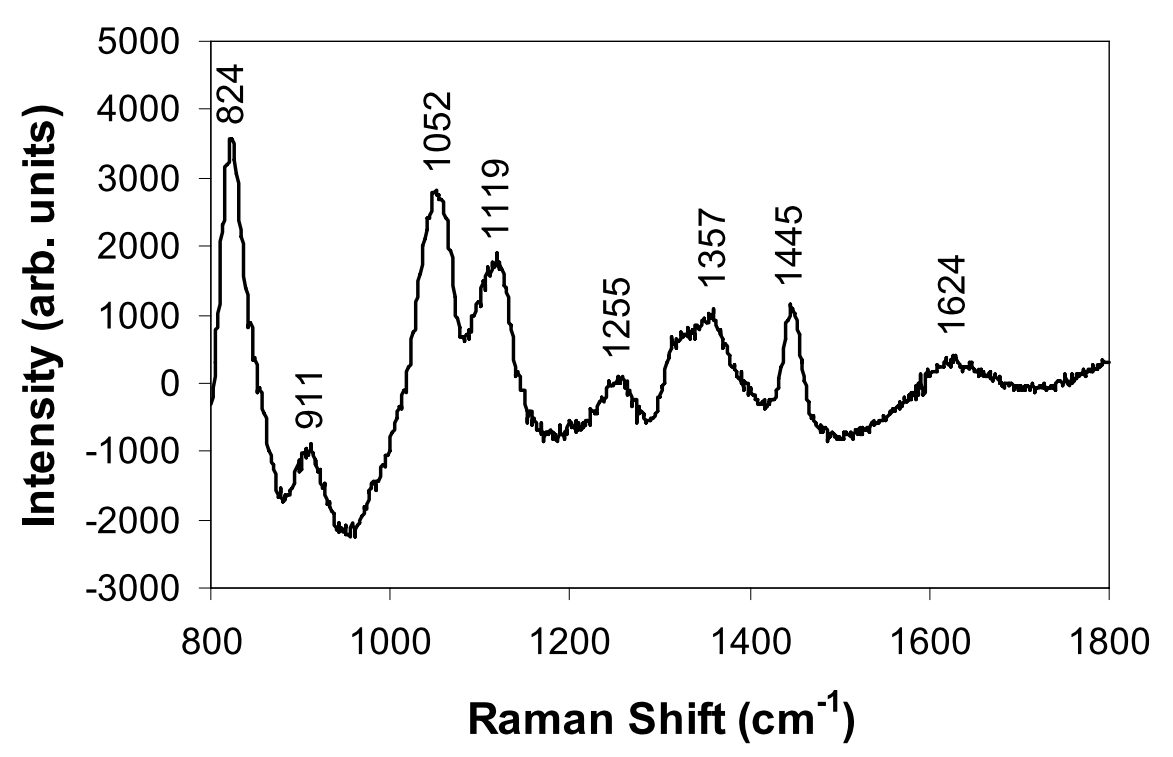

Fig. 3. Dispersive Raman spectrum of sucrose solution obtained from solubilization of refined sugar in water with concentration of $15.0 \mathrm{~g} / 100 \mathrm{ml}$. Laser power: $100 \mathrm{~mW}$, excitation wavelength: $830 \mathrm{~nm}$, resolution: $8 \mathrm{~cm}^{-1}$.

Table 1

Raman bands and vibrational group assignment for sucrose molecule

\begin{tabular}{ccc}
\hline Band $\left(\mathrm{cm}^{-1}\right)$ & Group & Band assignment \\
\hline 824 & $1,3,5$ tri substituted benzene & $\mathrm{CH}$ out-of-plane deformation \\
911 & $\mathrm{CH}=\mathrm{CH}_{2}$ & $\mathrm{CH}_{2}$ out-of-plane wagging \\
1052 & $\mathrm{CH}_{2}-\mathrm{O}-\mathrm{H}$ & $\mathrm{C}-\mathrm{O}$ stretching \\
1119 & $\mathrm{C}-\mathrm{O}-\mathrm{H}$ & $\mathrm{C}-\mathrm{O}$ stretching \\
1255 & $\mathrm{C}-\mathrm{O}-\mathrm{C}$ & $\mathrm{C}-\mathrm{O}-\mathrm{C}$ antisymetric stretching \\
1445 & $\mathrm{CH}_{2}$ & $\mathrm{CH}_{2}$ scissoring vibration \\
\hline
\end{tabular}

in the literature $[3,18]$. Table 1 presents the Raman bands identified in the spectra and the respective functional groups associated to these peaks, which have been assigned to several vibrational modes of the sucrose molecule. Raman bands of diluted sucrose samples were found in the same positions as the highly concentrated ones, despite the lower intensities as function of the respective concentrations (not shown). Since Raman scattering spectrum shows bands related to the vibrational frequencies of each bond in the sucrose molecule, there is a correlation between the intensity of each band and the final sample concentration. Therefore, a correlation between the concentration and the Raman intensity can be performed with significant precision. The Raman band at $1624 \mathrm{~cm}^{-1}$ can be attributed to the quartz cuvette used to hold the solutions [38].

Figure 4 presents the mean Raman spectra of four brands of lemon-type soft drinks. It was found a similarity between the spectra of all brands. The main Raman bands that appear in the spectra are characteristic peaks of sucrose, indicating the use of the same sweetener for all samples, with a small difference in the overall Raman bands intensities, evidencing a small difference in the quantity of sucrose of each brand.

By comparing the spectra of sucrose and the soft drinks, one observes that the sucrose is the main Raman scatterer, while other ingredients, such as the acidifier, the natural juice and the natural flavor 


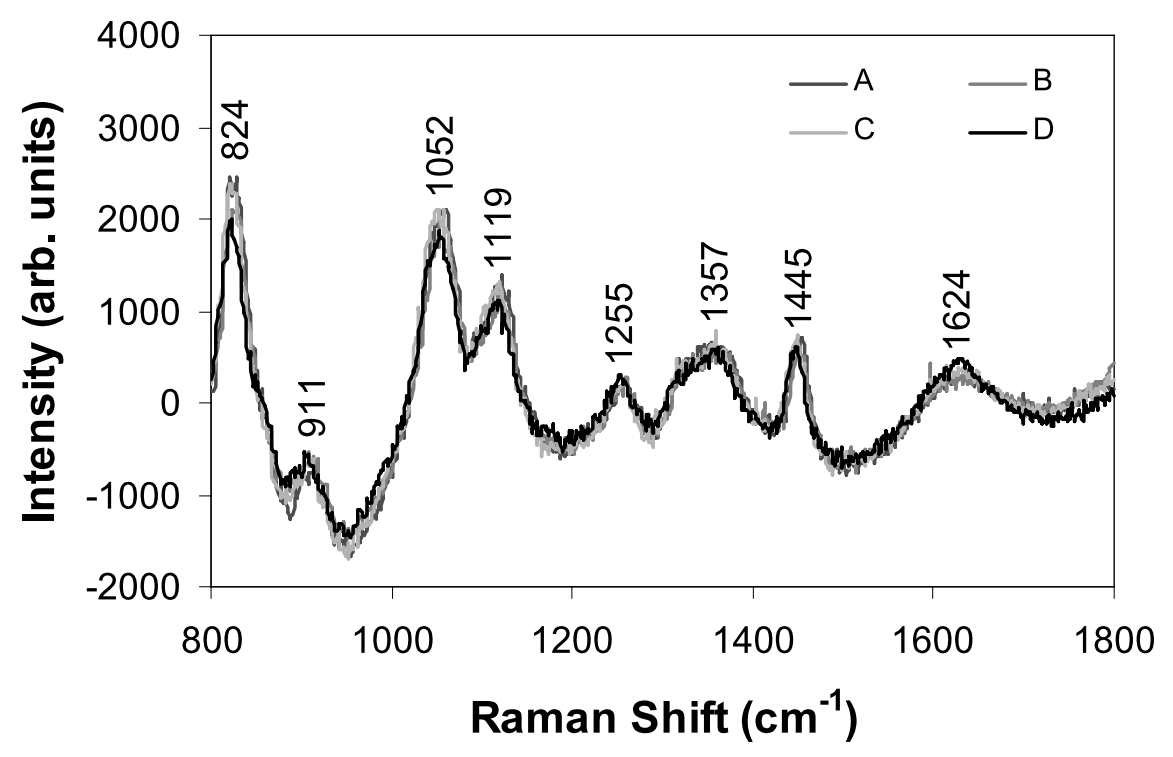

Fig. 4. Mean Raman spectra of lemon-type soft drinks from four different brands (mean calculated using 12 samples of each brand). Laser power: $100 \mathrm{~mW}$, excitation wavelength: $830 \mathrm{~nm}$, resolution: $8 \mathrm{~cm}^{-1}$.

that are present in the soft drink do not show an important Raman scattering. According to the British Pharmacopoeia, the intensity of Raman bands is directly proportional to the concentration of the components that are responsible by the sample scattering, implying that the spectral peak can be used to quantify the main ingredients [36].

In these experiments, it was used the PLS as a multivariate method for concentration prediction. Multivariate methods have demonstrated substantial advantages over standard, one variable tool. Indeed, PLS is a method which makes possible the inclusion of new variables, which are found to be correlated to the change in the concentrations, such as band shifts and others new bands that present concentrationdependent behavior [36]. This is not the case of the sucrose, although the multivariate model is robust and could address this possible problem.

The calibration curve constructed with the concentrations of sucrose $(\mathrm{g} / \mathrm{ml})$, which was obtained by the PLS, was plotted and can be seen in Fig. 5. The standard error of calibration (SEC) measures the error of the PLS model in predicting new concentrations. Possible errors in the calibration curve could be attributed to flaws in the preparation of the dilutions employed in the calibration process and the spectral shot noise is peculiar to the dispersive Raman instruments. In the curve of real concentration versus predicted concentration, it was possible to calculate the SEC, which was $0.30 \mathrm{~g} / 100 \mathrm{ml}$.

The calibration model using the sucrose dilutions was then applied in the Raman spectra of soft drinks using two latent variables (function plspred), and the predicted concentration of the sucrose presented in each sample was calculated. Table 2 shows the soft drinks sucrose concentration predicted by the PLS and the concentration displayed in each nutritional table. The error of the predicted concentration versus displayed concentration is also shown in Table 2. Only one sample (brand 1) showed an error above the SEC value $(5.2 \%$ or $0.6 \mathrm{~g} / 100 \mathrm{ml})$, with the predicted sucrose value being lower than the one informed by the Nutritional Table.

Chemometric techniques, such as PLS, have been important in the quantitative analysis of compounds present in complex samples [29,33]. These molecules, mainly organic ones, can be encountered in the samples as aggregates or submitted to several chemical interactions. Such chemical interactions can 


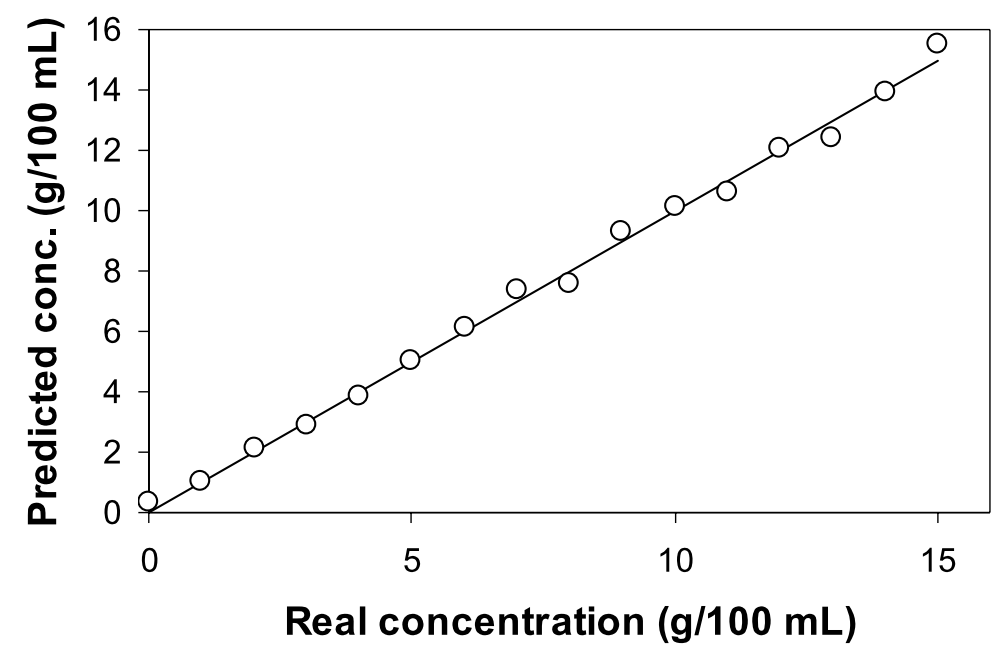

Fig. 5. Plot of the real concentration of sucrose dissolved in water versus predicted concentrations calculated by the PLS model applied to Raman spectra of soft drinks using two latent variables.

Table 2

Values of carbohydrates informed in the nutritional table compared to the sucrose concentration (mean - M and standard deviation - SD) provided by the PLS model

\begin{tabular}{lccc}
\hline Lemon-type soft drink & $\begin{array}{c}\text { Informed } \\
\text { concentration from } \\
\text { Nutritional Table } \\
(\mathrm{g} / 100 \mathrm{ml})\end{array}$ & $\begin{array}{c}\text { Predicted concentration } \\
\mathrm{M} \pm \mathrm{SD}\end{array}$ & Error $(\%)^{*}$ \\
& 11.5 & $\mathrm{~g} / 100 \mathrm{ml})$ & \\
\hline Brand A & 9.5 & $10.9 \pm 0.15$ & 5.5 \\
Brand B & 10.5 & $9.4 \pm 0.10$ & 1.1 \\
Brand C & 8.0 & $10.1 \pm 0.16$ & 3.8 \\
Brand D & $8.15 \pm 0.11$ & 1.9 \\
\hline
\end{tabular}

*Error between the carbohydrate amount from nutritional table and the mean predicted concentration.

increase the width of bands and change the band positions, decreasing significantly the resolution capability of the technique. In this context, it is possible to mention, for instance, the processed food, in which specific bands can overlap, being quite difficult to separate these variables from the spectrum without a robust and reliable technique. Therefore, a chemometric tool like PLS would help processing the information obtained from spectrographs and multichannel detectors, where various information are recorded in a single spectrum. In fact, PLS is an effective chemometric tool when handling with noisy signals, allowing calibration even in the presence of interferences [35].

The correct quantification of food composition is important for diet purposes and, in case of quality control in industries, the advantages of using Raman spectroscopy at the production line, the amount of a specific compound could be determined in real time in line [15]. Moreover, this resource would also useful by government institutions such as FDA or the equivalent food and drugs quality control government organism of countries for monitoring the consumed products. 


\section{Conclusions}

In this study, it was verified the potential of dispersive Raman spectroscopy applied to soft drink quality control for evaluating the nutritional specifications listed on the nutritional table of products, aiming the quality assurance and monitoring. Furthermore, this technique associated with the chemometric method PLS showed to be effective in quantifying the sucrose in lemon-type soft drinks. By developing a calibration curve using the Raman spectra of known concentrations of sucrose dissolved in water one could evaluate the sucrose amount with a low prediction error. The results indicate that the quantity of sucrose in the beverages analyzed meets the values set on the nutritional tables.

\section{Acknowledgement}

V.G.B. Conceição thanks Master fellowship from CAPES/PROSUP (Ministry of Education, Brazil).

\section{References}

[1] M. Fisberg, O.M.S. Amancio and A.M.P. Lottenberg, Soft drinks consumption and the human health, Pediatr. Mod. 38 (2002), 1-12.

[2] Ministério da Saúde, Agência Nacional de Vigilância Sanitária - ANVISA, Gerência-Geral Alimentos, Resolução CNNPA $\mathrm{n}^{\mathrm{o}}$ 12, de 24/071978, available at: http://www.anvisa.gov.br/legis/resol/12_78.pdf.

[3] M. Mathlouthi, C. Luu, A.M. Meffroy-Biget and D.V. Luu, Laser-Raman study of solute-solvent interactions in aqueous solutions of D-fructose, D-glucose, and sucrose, Carbohydr. Res. 81 (1980), 203-212.

[4] H. Basciano, L. Federico and K. Adeli, Fructose, insulin resistance, and metabolic dyslipidemia, Nutr. Metab. 2 (2005), $1-14$.

[5] W.C. Willett, Dietary fat plays a major role in obesity, Obes. Rev. 3 (2002), 59-68.

[6] K.L. Morris and M.B. Zemel, Glycemic index, cardiovascular disease, and obesity, Nutr. Rev. 57 (1999), $273-276$.

[7] T.S. Cunha, V. Faraha, J. Paulini, M. Pazzine, K.M. Elased, F.K. Marcondes, M.C. Irigoyen, K. De Angelis, L.D. Mirkin and M. Morris, Relationship between renal and cardiovascular changes in a murine model of glucose intolerance, Regul. Pept. 139 (2007), 1-4.

[8] M. Fisberg, C.R.S. Bandeira, E.A. Bonilha, G. Halpern and M.D. Hirschbruch, Hábitos alimentares na adolescência, Pediatr. Mod. 36 (2000), 724-734.

[9] C.R.M. Frazier, P. Mason, X. Zhuang and J.A. Beeler, Sucrose exposure in early life alters adult motivation and weight gain, PLOS ONE 3 (2008), 3221.

[10] Ministério da Saúde, Secretaria de Assistência à Saúde, Departamento de Atenção Básica, Coordenação da Política de Alimentação e Nutrição. Pesquisa de Orçamentos Familiares (POF), 2002/2003, available at: http://portal.saude.gov.br/portal/aplicacoes/noticias/noticias_detalhe.cfm?co_seq_noticia=28219.

[11] C.P. Mendonça and L.A. dos Anjos, Dietary and physical activity factors as determinants of the increase in overweight/obesity in Brazil, Cad. Saúde Pública 20 (2004), 698-709.

[12] R.N. Silva, V.N. Monteiro, J.X. Alcanfor, E.M. Assis and E.R. Asquieri, Comparação de métodos para a determinação de açúcares redutores e totais em mel, Ciência Tecnol. Alime. 23 (2003), 337-341.

[13] N. Ghosh, Y. Verma, S.K. Majumder and P.K. Gupta, A fluorescence spectroscopic study of honey and cane sugar syrup, Food Sci. Technol. Res. 11 (2005), 59-62.

[14] S. Keller, T. Löchte, B. Dippel and B. Schrader, Quality control of food with near-infrared-excited Raman spectroscopy, Fresenius J. Anal. Chem. 346 (1993), 863-867.

[15] F. Adar, R. Geiger and J. Noonan, Raman spectroscopy for process/quality control, J. Appl. Spectrosc. Rev. 32 (1997), $45-101$.

[16] M.A. Strehle, P. Rösch, M. Baranska, H. Schulz and J. Popp, On the way to a quality control of the essential oil of fennel by means of Raman spectroscopy, Biopolymers 77 (2005), 44-52.

[17] T. Vankeirsbilck, A. Vercauteren, W. Baeyens, G. Van der Weken, F. Verpoort, G. Vergote and J.P. Remon, Applications of Raman spectroscopy in pharmaceutical analysis, Trends Analyt. Chem. 21 (2002), 869-877.

[18] A. Celedon and J.M. Aguilera, Applications of microprobe Raman spectroscopy in food science, Food Sci. Technol. Int. 8 (2002), 101-108. 
[19] E.B. Hanlon, R. Manoharan, T.W. Koo, K.E. Shafer, J.T. Motz, M. Fitzmaurice, J.R. Kramer, I. Itzkan, R.R. Dasari and M.S. Feld, Prospects for in vivo Raman spectroscopy, Phys. Med. Biol. 45 (2000), R1-R59.

[20] P. Carmona, M. Molina and A. Rodrígues-Casado, Raman study of the thermal behaviour and conformational stability of basic pancreatic trypsin inhibitor, Eur. Biophys. J. 32 (2003), 137-143.

[21] M. Sohn, D.S. Himmelsbach, S.E. Kays, D.D. Archibald and F.E. Barton, NIR-FT/Raman spectroscopy for nutritional classification of cereal foods, Cereal Chem. 82 (2005), 660-665.

[22] P.D.A. Pudney, T.M. Hancewicz and D.G. Cunningham, The use of confocal Raman spectroscopy to characterise the microstructure of complex biomaterials: foods, Spectroscopy 16 (2002), 217-225.

[23] M. Hwang, S. Cho, H. Chung and Y. Woo, Nondestructive determination of the ambroxol content in tablets by Raman spectroscopy, J. Pharm. Biomed. Anal. 38 (2005), 210-215.

[24] C. Eliasson, N.A. Macleod, L.C. Jayes, F.C. Clarke, S.V. Hammond, M.R. Smith and P. Matousek, Non-invasive quantitative assessment of the content of pharmaceutical capsules using transmission Raman spectroscopy, J. Pharm. Biomed. Anal. 47 (2008), 221-229.

[25] L.M. Moreira, L. Silveira Jr., F.V. Santos, J.P. Lyon, R. Rocha, R.A. Zângaro, A.B. Villaverde and M.T.T. Pacheco, Raman spectroscopy: A powerful technique for biochemical analysis and diagnosis, Spectroscopy 22 (2008), 1-19.

[26] H. Schulz and M. Baranska, Identification and quantification of valuable plant substances by IR and Raman spectroscopy, Vib. Spectrosc. 43 (2007), 13-25.

[27] V. Baeten and R. Aparicio, Edible oils and fats authentication by Fourier transform Raman spectrometry, Biotechnol. Agron. Soc. 4 (2000), 196-203.

[28] R.J. Yatka, M.J. Grenberg, M.T. Bunkzec, R.L. Whistler and M.A. Reed, U.S. Patent Institute 5 (1998), 800-848.

[29] M.A. Morgano, C. Moriya and M.M.C. Ferreira, Determinação quantitativa do teor de sacarose em açúcar por espectroscopia FT-IR/ATR e regressão PLS, Braz. J. Food Technol. 6 (2003), 77-83.

[30] R. Goodacre, B.S. Radovic and E. Anklam, Progress toward the rapid nondestructive assessment of the floral origin of European honey using dispersive Raman spectroscopy, Appl. Spectrosc. 56 (2002), 521-527.

[31] C. Krafft and V. Sergo, Biomedical applications of Raman and infrared spectroscopy to diagnose tissues, Spectroscopy 20 (2006), 195-218.

[32] L.S. Mendes, F.C.C. Oliveira, P.A.Z. Suarez and J.C. Rubim, Determination of ethanol in fuel ethanol and beverages by Fourier transform (FT)-near infrared and FT-Raman spectrometries, Anal. Chim. Acta 493 (2003), 219-231.

[33] Y.Z. Liang and O.M. Kvalheim, Robust methods for multivariate analysis - a tutorial review, Chemometr. Intell. Lab. 32 (1996), 1-10.

[34] M.M.C. Ferreira, A.M. Antunes, M.S. Melgo and P.L.O. Volpe, Chemometrics I: multivariate calibration, a tutorial, Quím. Nova 22 (1999), 724-731.

[35] A.P. Cunha, V.P. Cunha, L. Silveira Jr. and A.A. Martin, Calibration model of methylmetacrylate concentration in aqueous solution using ultraviolet absorption spectroscopy, Quím. Nova 26 (2003), 850-854.

[36] British Pharmacopeia (on line) v.I \& II. (2008). Monographs: Medicinal and pharmaceutical substances sucrose, available at: http://www.pharmacopoeia.co.uk/ixbin/bp.cgi?r=bsz9BHr0Vlf\&id=6017\&n=16\&a=display.

[37] J.C. Lázaro, M.T.T. Pacheco, K.C. Rodrigues, C.J Lima, L.M. Moreira, A.B. Villaverde and L. Silveira Jr., Optimizing the Raman signal for characterizing organic samples: The effect of slit aperture and exposure time, Spectroscopy 23 (2009), 71-80.

[38] J. Saade, M.T.T. Pacheco, M.R. Rodrigues and L. Silveira Jr., Identification of hepatitis C in human blood serum by near-infrared Raman spectroscopy, Spectroscopy 22 (2008), 387-395. 


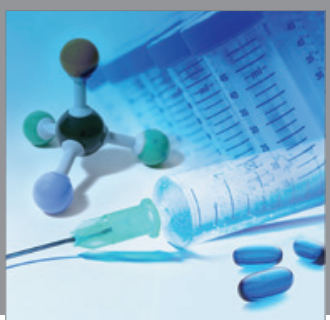

International Journal of

Medicinal Chemistry

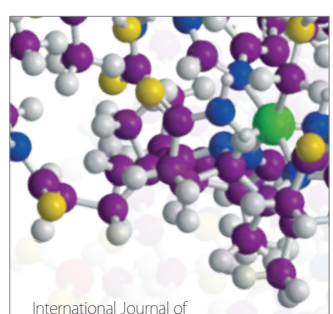

Carbohydrate Chemistry

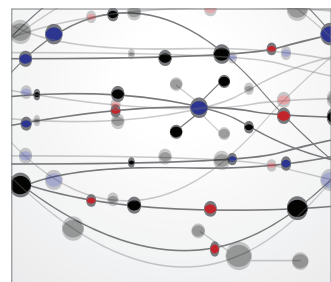

The Scientific World Journal
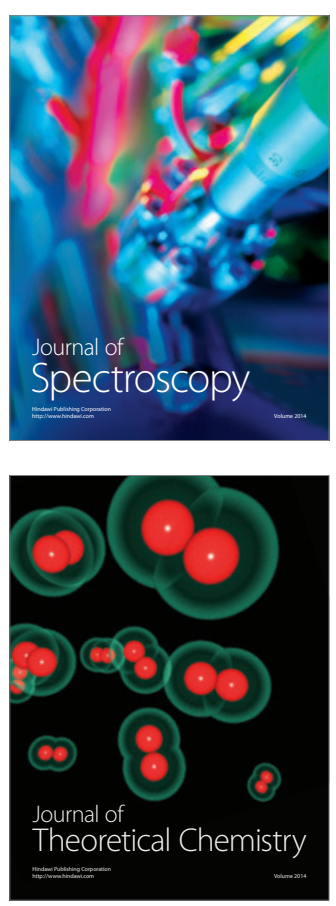
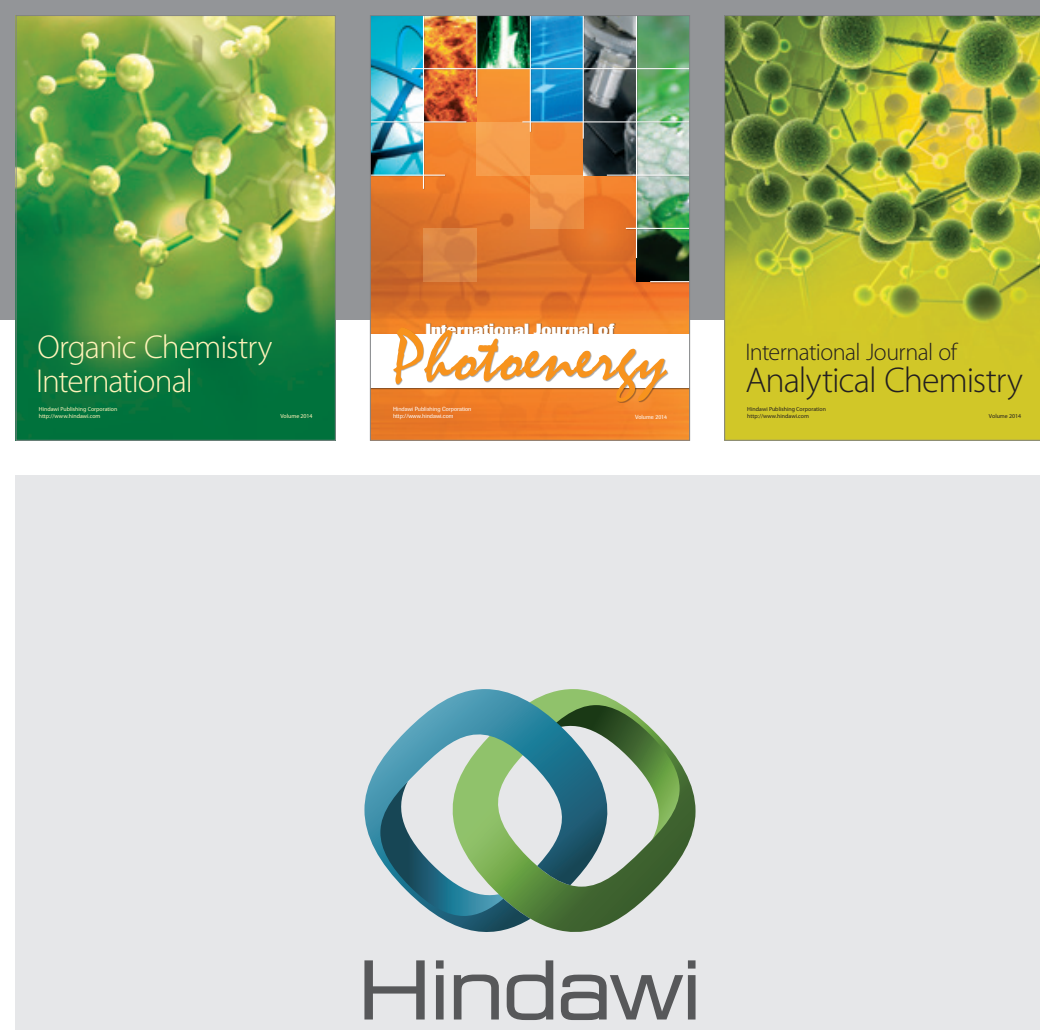

Submit your manuscripts at

http://www.hindawi.com
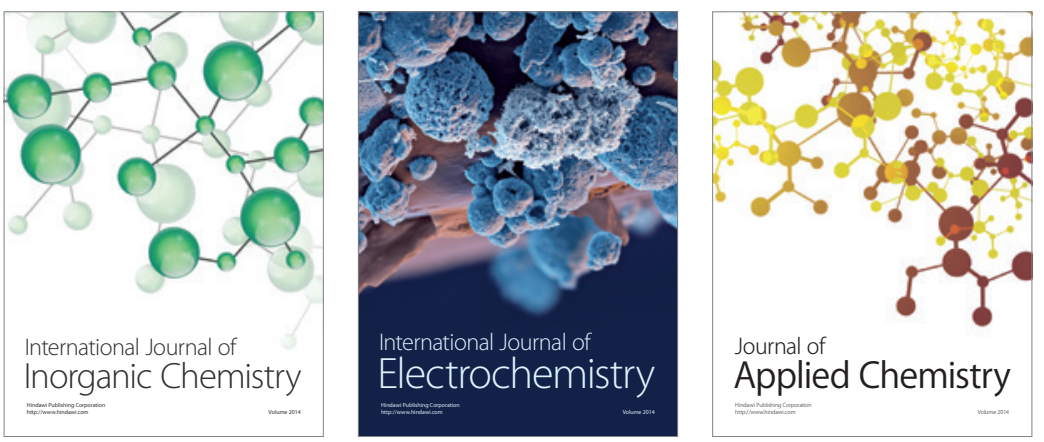

Journal of

Applied Chemistry
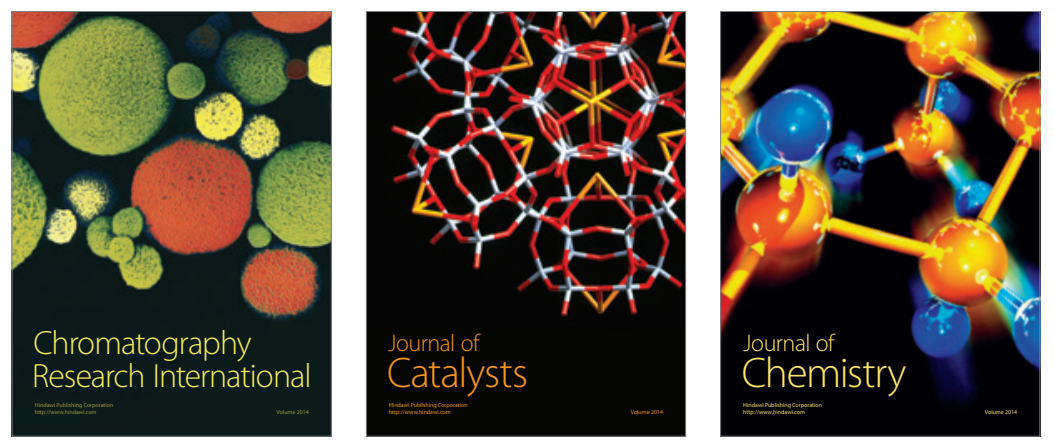
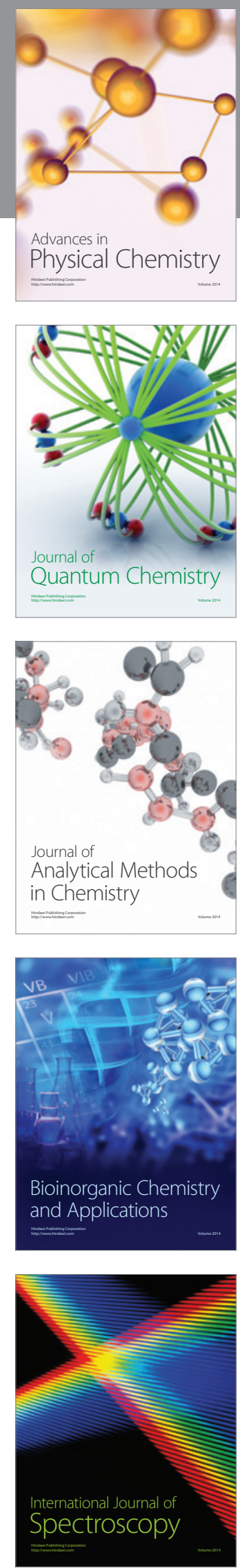